\title{
EL DEBER DE PROTEGER LA VIDA, Y ESPECIALMENTE DE LOS MÁS DEBILITADOS, FRENTE A UN INEXISTENTE DERECHO A QUITARSE LA VIDA POR SÍ O POR OTROS
}

The duty to protect life, and especially that of the most weakened, against to a non-existing right to take one's own life by oneself or by others

\author{
JOSÉ LUIS MARTÍNEZ LÓPEZ-MUÑIZ \\ Universidad de Valladolid \\ marlomu@der.uva.es
}

Cómo citar/Citation

Martínez López-Muñiz, J. L. (2021)

El deber de proteger la vida

y especialmente de los más debilitados, frente a un inexistente

derecho a quitarse la vida por sí o por otros.

Revista Española de Derecho Constitucional, 122, 47-83.

doi: https://doi.org/10.18042/cepc/redc.122.02

Resumen

El Tribunal Europeo de Derechos Humanos, en su interpretación sobre los derechos a la autonomía personal y a la vida, solamente ha encontrado base en el primero sin lesionar el segundo en la opción voluntaria y libre por la abstención terapéutica o contra un mantenimiento vital artificial, bajo determinadas condiciones. En sentencia de 26 de febrero de 2020, el Tribunal Constitucional alemán ha tergiversado esa doctrina jurisprudencial europea, que, en Espańa, tiene valor cuasiconstitucional y converge con la jurisprudencia hasta ahora dimanada de su Tribunal Constitucional. Similar doctrina se desprende de la jurisprudencia del Tribunal Supremo de los Estados Unidos de América. Tres consideraciones principales respaldan esa doctrina: la libertad propia de la dignidad de toda persona humana no incluye 
eliminarla, nadie puede matar a otro salvo legítima defensa proporcionada, y hay un deber social y del Estado de proteger cualquier vida.

\title{
Palabras clave
}

Derecho a la vida; derecho a la autonomía personal; suicidio asistido; eutanasia; dignidad.

\begin{abstract}
European Court of Human Rights, interpreting the rights to personal autonomy and life, has only found a basis in the first without injuring the second in the voluntary and free option for therapeutic abstention or against artificial life support, under certain conditions. In a ruling of February 26, 2020, the German Constitutional Court has misrepresented this European jurisprudential doctrine, which in Spain has a quasi-constitutional value and is convergent with case-law so far emanated from its Constitutional Court. A such similar doctrine derives from the Supreme Court of United States of America. Three main considerations back this doctrine: the freedom that is proper to the dignity of every human person does not include eliminating it, no one can kill another except for proportionate legitimate defense, and there is a social and State duty to protect any life.
\end{abstract}

\section{Keywords}

Right to life; right to personal autonomy; assisted-suicide; euthanasia; dignity. 


\section{SUMARIO}

I. CUANDO EL LEGISLADOR DEL ESTADO ESPAÑOL SE DISPONE A APROBAR UNA LEY REGULADORA DE LA EUTANASIA. II. EL DERECHO A LA VIDA PROCLAMADO POR EL CONVENIO EUROPEO DE DERECHOS HUMANOS NO COMPORTA UN DERECHO A LA MUERTE: SENTENCIA PRETTY DE 2002 DEL TRIBUNALEUROPEO DEDERECHOS HUMANOS. III. EL TRIBUNAL EUROPEO DE DERECHOS HUMANOS SOLO HA AMPARADO EN EL ARTÍCULO 8 DEL CONVENIO LA OPCIÓN, BAJO CIERTAS CONDICIONES, POR LA ABSTENCIÓN TERAPÉUTICA, NUNCA EL SUICIDIO ASISTIDO O LA EUTANASIA. IV. TERGIVERSACIÓN SORPRENDENTE DE LA JURISPRUDENCIA DEL TRIBUNAL EUROPEO DE DERECHOS HUMANOS POR EL TRIBUNAL CONSTITUCIONAL FEDERAL ALEMÁN EN SU SENTENCIA DE 26 DE FEBRERO DE 2020. V. LA CUESTIÓN BAJO LA CONSTITUCIÓN ESPAÑOLA. VI. PRONUNCIAMIENTOS CLAROS DEL TRIBUNAL SUPREMO NORTEAMERICANO. VII. TRES CONSIDERACIONES CENTRALES A MODO DE CONCLUSIÓN. BIBLIOGRAFIA.

\section{CUANDO EL LEGISLADOR DEL ESTADO ESPAÑOL SE DISPONE A APROBAR UNA LEY REGULADORA DE LA EUTANASIA}

El PSOE ya lo había propuesto con anterioridad ${ }^{1}$, pero ha sido la presentación, por el Grupo Socialista del Congreso, de la Proposición de Ley Orgánica de regulación de la eutanasia publicada en el $B O C G-C D$ (XIV legislatura) del 31 de enero de 2020, n. $46-1$, la que ha puesto en marcha el procedimiento legislativo que, cuando se terminan de escribir estas líneas en diciembre

1 BOCG-CD, XII legislatura, B-270-1, 21 de mayo de 2018; aquella proposición fue tomada en consideración el 26 de junio, tras la llegada al Gobierno de Pedro Sánchez pocos días antes, pero decayó al concluirse la legislatura. Ha sido analizada por Marcos del Cano (2019a; 2019b). Unidas Podemos y confederados había presentado un año antes una proposición similar (BOCG-CD B-77-1, 3 de enero), rechazada el 21 de marzo de 2017. En la breve XIII legislatura, tras las elecciones del 28 de abril, el Grupo Socialista volvió a presentar similar proposición (BOCG-CD, B-64-1, 30 de julio de 2019), tomada en consideración el 10 de septiembre; caducó por la extinción de la legislatura el 24 de septiembre. Había, asimismo, presentado otra proposición análoga, pocos días antes, Unidas Podemos y confederados (BOCG-CD 62-1, 22 de julio), sin que se llegara a su toma en consideración. 
de 2020, parece abocado a introducir en España una despenalización regulada de lo que su texto denomina la «ayuda necesaria para morir», haciéndola objeto expresamente de un "derecho a solicitarla y recibirla» bajo determinadas «condiciones» (art. 1). La eufemísticamente denominada «ayuda a morir» se traduce, en realidad, al menos en el texto originario de la proposición al que nos referimos, en que una persona —en realidad un profesional sanitario (art. 11) — mate a otra (art. 3.g.i) o le proporcione los medios circunstancialmente imprescindibles para que se mate a sí misma (art. 3.g.ii), si así lo pide ella o se suponga que así lo quiere por una declaración hecha antes de resultar incapaz (art. 5.2). Condición para «disfrutar» de tal derecho sería «sufrir una enfermedad grave e incurable o grave, crónica e invalidante en los términos establecidos en esta ley, certificada por el médico o médica responsable» (art. 5.1.d). La tal «ayuda para morir estará incluida en la Cartera de servicios comunes del Sistema Nacional de Salud y será de financiación pública» (art. 13.1). Una disposición adicional primera afirma, en el colmo de la contradicción y de la antiverdad, que «la muerte producida derivada de la prestación de ayuda para morir tendrá la consideración de muerte natural a todos los efectos».

La proposición de ley mantendría, no obstante, la vigencia del art. 143 del Código Penal en sus tres primeros apartados, donde castiga la inducción al suicidio con prisión de cuatro a ocho años, y la cooperación al suicidio con prisión de dos a cinco años, que puede llegar a ser de seis a diez años «si la cooperación llegara hasta el punto de ejecutar la muerte». Su disposición final primera se limitaría a sustituir la redacción de su apdo. 4 por otra que declararía «no punible» solo específicamente «la conducta del médico o médica que con actos necesarios y directos causare o cooperare a la muerte de una persona, cuando esta sufra una enfermedad grave e incurable o enfermedad grave, crónica e invalidante, en los términos establecidos en la normativa sanitaria».

La despenalización se reduce, pues, en realidad, a una exoneración de penas al personal facultativo $-y$ bajo las condiciones de la nueva ley- y vendría a sustituir por entero a la aminoración de penas que el Código Penal de 1995, por razones consideradas humanitarias, había introducido en este apartado de manera general para la ayuda al suicidio —incluida la causación de la muerte- en supuestos de enfermedad grave o generadora de graves padecimientos. El Congreso de los Diputados ha decidido, no obstante, mantener, con retoques redaccionales, la reducción de penas establecida en dicho apdo. 4, y añadir un nuevo apdo. 5 para la exoneración «de responsabilidad penal de quien causare o cooperare activamente a la muerte de otra persona cumpliendo lo establecido en la Ley Orgánica reguladora de la Eutanasia». Lo que viene a sintetizar lo mismo que pretendía originariamente la 
proposición, aunque ahora sin dejar de mantener aminorada la responsabilidad de los que hicieran lo mismo, pero sin ser facultativos sanitarios y sin sujetarse a lo dispuesto en la nueva ley orgánica.

A la vista de esta iniciativa legislativa, 162 profesores y académicos de Derecho - 82 de ellos catedráticos-, vinculados a 37 universidades y varias Reales Academias de Jurisprudencia y Legislación ${ }^{2}$, suscribimos una declaración pública a primeros de octubre de 2020, que enviamos al Congreso, pidiendo la retirada de esa proposición de ley por entender que «constituye una grave amenaza a la seguridad de los más mayores y enfermos [...] y es contraria a la dignidad de la persona humana y a los derechos más fundamentales que le son inherentes, garantizados por la Constitución y el Derecho internacional de los derechos humanos como base irrenunciable de nuestra civilización» ${ }^{3}$.

Con independencia de las aportaciones al tema que, en diversos momentos y medios, antes o después de esa declaración, han hecho varios de los que la suscribieron, me sentí acuciado, como primer firmante, a analizar con más detenimiento el tema, particularmente en punto a su tratamiento en la jurisprudencia de nuestro Tribunal Constitucional y del Tribunal Europeo de Derechos Humanos - ya muy glosado por la doctrina-, lo que me ha parecido conveniente complementar con una atención a la aún reciente sentencia del Tribunal Constitucional alemán de febrero de 2020 y con la posición mantenida por el Tribunal Supremo de Estados Unidos. A la vista de todo ello me ha parecido obligado deducir algunas conclusiones relevantes para lo que pudiera ser un futuro juicio de constitucionalidad sobre la ya previsible ley de eutanasia para España, que he prolongado con algunos razonamientos jurídicos que propongo, no sin algún diálogo con diversos pronunciamientos ya efectuados por distintos sectores de la doctrina.

\section{EL DERECHO A LA VIDA PROCLAMADO POR EL CONVENIO EUROPEO DE DERECHOS HUMANOS NO COMPORTA UN DERECHO A LA MUERTE: SENTENCIA PRETTY DE 2002 DEL TRIBUNAL EUROPEO DE DERECHOS HUMANOS}

Lo dejó dicho bien claramente el TEDH en su sentencia Pretty c. Reino Unido de 2002:

2 Sus nombres y posición se hicieron accesibles en https://bit.ly/3gRhL1Z.

3 Considerábamos en concreto que la proposición es contraria a los arts. 10, 14, 15, 43.1, 49 y 50 CE. 
El art. 2 [del CEDH de 1950, que afirma la protección por la ley del «derecho de toda persona a la vida» y determina estrictamente los supuestos en que, excepcionalmente, alguien puede ser privado de la suya intencionadamente] no puede, sin distorsión del lenguaje, ser interpretado como si otorgase el derecho que se le opone diametralmente, esto es un derecho a morir; ni puede crear un derecho a la autodeterminación en el sentido de habilitar a un individuo para elegir la muerte antes que la vida (apdo. 39) ${ }^{4}$.

Ha llamado la atención, y convendrá retenerlo aquí, la forma peculiar en que está redactado el citado precepto del Convenio Europeo — «El derecho de toda persona a la vida está protegido por la ley. Nadie podrá ser privado de su vida intencionadamente»—, ya que, «en lugar de reconocer directamente el derecho a la vida, impone a las autoridades estatales la obligación de proteger el derecho de todas las personas a la vida, junto con la prohibición de la privación intencionada de la vida» (Ochoa Ruiz, 2018: 2).

La sentencia Pretty remachó lo dicho aseverando que «el Tribunal, de acuerdo con esto, entiende que derecho alguno a morir a manos de tercera persona o con la asistencia de la autoridad pública, puede derivarse del art. 2 de la Convención» (apdo. 40), lo que, además, dice confirmarse por la Recomendación 1418 (1999) de la Asamblea Parlamentaria del Consejo de Europa, en la que encargó al Comité de Ministros que alentase a los Estados del Consejo de Europa «a respetar y proteger la dignidad de los enfermos terminales y de las personas moribundas a todos los efectos", y en particular "manteniendo la prohibición de privarles intencionalmente de su vida», «reconociendo que el deseo de morir de un enfermo terminal o de una persona moribunda nunca constituye una pretensión legal de morir a manos de otra persona» y que tampoco "puede constituir por sí mismo una justificación legal para llevar a cabo actuaciones dirigidas a provocar su muerte» (apdo. 24 de la sentencia cit.).

En la misma sentencia, el Tribunal de Estrasburgo no tuvo reparo en proclamar la «sacralidad de la vida como un principio protegido por la Convención [de Derechos Humanos]», al afirmar también que siendo "la verdadera esencia de la Convención el respeto de la dignidad humana y de la libertad humana», consideraba que, «sin negar de ningún modo» dicho principio (que, por ende, se mantendría como límite infranqueable), «bajo el art. 8 [que protege el derecho al respeto de la vida privada] alcanzan significación

4 Bastantes autores han argumentado que no existe un «derecho» de la persona a la muerte y que tampoco cabe admitirla como «libertad» jurídicamente amparable. Vid., por ejemplo, Sánchez Sáez (2020: passim). 
nociones sobre la calidad de vida», de modo que «en una era de creciente sofisticación médica combinada con más largas expectativas de vida, mucha gente está interesada en no ser forzada a perdurar en su ancianidad o en estados de avanzada decrepitud física o mental en conflicto con ideas firmemente sostenidas sobre la identidad propia y personal» (apdo. 65). Y si bien, en este contexto, el Tribunal parece encontrar ahí razones justificadas contra la obstinación terapéutica o incluso la imposición de tratamientos médicos en determinados supuestos, en ningún momento sostiene que el derecho a la autonomía personal que pueda derivar del citado art. 8 pueda amparar cualquier desconocimiento de la protección de la vida del art. 2. La opción por un determinado modo de morir a la que alude en algún momento se refiere siempre solo a la elección de una muerte por causas naturales en lugar de un hipotético alargamiento artificial de la vida por tratamientos médicos, pero nunca a la de una muerte de causalidad intencional humana, producida por uno mismo o por un tercero o con su ayuda ${ }^{5}$. Insistimos en ello a continuación.

\section{EL TRIBUNAL EUROPEO DE DERECHOS HUMANOS SOLO HA AMPARADO EN EL ARTÍCULO 8 DEL CONVENIO LA OPCIÓN, BAJO CIERTAS CONDICIONES, POR LA ABSTENCIÓN TERAPÉUTICA, NUNCA EL SUICIDIO ASISTIDO O LA EUTANASIA}

En otra sentencia más cercana al momento actual, de 5 de junio de 2015 , en el asunto Lambert y otros c. Francia, que, dictada por la Gran Sala del Tribunal, es tenida como el exponente más neto de la doctrina del Tribunal sobre estos extremos (como se afirma, por ejemplo, en la decisión sobre el asunto Gard c. Reino Unido de 27 de junio de 2017), el Tribunal Europeo ha tenido buen cuidado de advertir expresamente que «en el presente asunto no se le ha planteado la cuestión de la eutanasia, sino únicamente la de la interrupción de un tratamiento que mantiene la vida artificialmente» (apdo. 141), y que cuanto afirmará en esa sentencia, interpretando y aplicando al caso «la obligación» que el art. 2 del Convenio «impone al Estado», "de no sólo abstenerse de matar "intencionalmente" (obligaciones negativas) sino también de tomar las medidas necesarias para proteger la vida de las personas sometidas a su jurisdicción (obligaciones positivas)» (apdo. 117), solo se referirá a estas

5 Ha sido muy común alterar el sentido de lo dicho en Pretty por no tenerlo en cuenta: así, Gerards (2006: 356-357), Grabenwarter (2014: 15, 22 y 190-191) y otros muchos, también en la doctrina española, incluidos Prieto Álvarez (2017: 199-200) o Rodríguez Portugués (2020: 236). 
obligaciones positivas, ya que, «en el contexto de la legislación francesa, que prohíbe causar intencionadamente la muerte y tan solo permite en ciertas circunstancias interrumpir o no iniciar tratamientos que mantienen la vida artificialmente, el Tribunal considera que el presente asunto no pone en juego las obligaciones negativas del Estado» (apdo. 124), es decir, no se trata en modo alguno de avalar que pueda matarse a otro intencionalmente y más en concreto por parte del Estado o del personal médico de sus centros médicos.

El Tribunal advierte, además, claramente, en el apdo. 136 de la sentencia, que no había decidido nunca hasta entonces la específica cuestión planteada en el caso, pues, como recuerda en el apdo. 137, en 2009, en el asunto Sanles Sanles c. España (relativo al conocido caso de Ramón Sampedro), en que se pretendía poder "poner fin a [la propia] vida con la ayuda de terceros", con el argumento del «derecho a una muerte digna», el Tribunal no había entrado en el fondo del asunto, por estimar la demanda inadmisible por haber ya fallecido el interesado y carecer de legitimación el demandante, en 2002 se había pronunciado en la sentencia Pretty del modo ya dicho ante un caso de enfermedad degenerativa incurable de una señora, en el que el orden penal británico no permitía que su esposo le ayudara a suicidarse, lo que el Tribunal entendió que no contravenía al Convenio, y algo similar había venido a decir más tarde en su sentencia Haas, de 2011 - a propósito de una persona con trastorno bipolar que se quejaba de no poder obtener sin prescripción médica la sustancia letal que le permitiese cumplir su deseo de acabar con sus días sin que tampoco llegara a entrar en ello en Koch, de 2012, en un asunto análogo de una señora paralizada y con ventilación artificial (apdo. 137), porque realmente lo que hizo aquí fue limitarse a estimar que se había violado el art. 8.2 del Convenio por los tribunales alemanes al rechazar examinar la reclamación de la demandante ${ }^{7}$. Entendió también el Tribunal —apdo.

6 En el apdo. 52 de Haas c. Suiza, en el contexto de una legislación, la suiza, que admitía la ayuda al suicidio bajo ciertas condiciones, lo que no fue cuestionado ante el Tribunal y este excluyó de su valoración, el Tribunal dijo que la cuestión discutida no se refería «a la libertad de morir y la eventual impunidad de la persona que presta su ayuda a un suicidio», sino a la de «si, en virtud del artículo 8, el Estado debe procurar que el demandante pueda obtener pentobarbital sódico sin receta médica, haciendo una excepción a la Ley, para que pueda morir sin dolor y sin riesgo de fracaso». Volvemos sobre ello al tratar más delante de la sentencia alemana de 2020.

7 Resulta completamente gratuito afirmar por ello que la sentencia Koch c. Alemania, de 19 de julio de 2012, revele "que el Tribunal europeo de derechos humanos se está poniendo "serio" respecto de este tipo de casos y muestra una alta predisposición a valorar la autonomía del paciente y de sus familiares respecto de las decisiones sobre 
138 - que tampoco se habría encarado específicamente con la cuestión cuando en Glass, en 2003, rechazó que se hubiera violado el derecho a la vida del art. 2 del Convenio por haberse administrado diamorfina al hijo enfermo de los recurrentes, por parte de los médicos del hospital, y haberse hecho por uno de estos indicación de "no reanimar», pero sin intención alguna de provocar o acelerar la muerte (apdo. 123), y menos aún en los asuntos Burke c. Reino Unido, en 2006, y Ada Rossi y otros, en 2008, en los que el Tribunal hubo de inadmitir las demandas por defectos formales.

Es exclusiva y precisamente en este contexto como el Tribunal, tras recordar en esta sentencia Lambert lo dicho en Haas sobre «que el Convenio debe ser leído como un todo", integrándose adecuadamente el derecho a la vida del art. 2 y el derecho al respeto a la vida privada del 8 , «así como a la noción de autonomía personal que incluye», reitera también lo afirmado en el apdo. 51 de esta misma sentencia: que «el derecho de un individuo a decidir de qué manera y en qué momento debe terminar su vida era uno de los aspectos del derecho al respeto de su vida privada» (apdo. 142). Se está siempre hablando solo de la no imposición de tratamientos médicos ${ }^{8}$, por más que el Tribunal a la vez «constata que no existe consenso entre los Estados miembros del Consejo de Europa en permitir la interrupción de un tratamiento que mantenga la vida artificialmente, incluso si una mayoría de los Estados parece que la autorizan» (apdo. 147) 9 .

No lo está diciendo hace décadas, sino en 2015, hace cinco años. Aunque añada - siempre en este contexto- que sí que "existe, no obstante, un consenso sobre el papel primordial de la voluntad del paciente en la toma de decisiones, sea cual sea el modo de expresarla» (apdo. 147).

el final de la vida» (Rey, 2019: 33). Dada la posición subsidiaria que tiene el Tribunal con respecto a los órganos jurisdiccionales de cada Estado vinculado por el Convenio, el señalar que los tribunales alemanes debieron examinar la aplicación del art. 8.2 del Convenio antes de llevarse esta cuestión ante él no presenta el menor síntoma de haberse otorgado con ello una importancia especial a la autonomía sobre las decisiones sobre el final de la vida.

8 Traslada, por tanto, una idea muy equivocada de la realidad jurisprudencial del TEDH afirmar que «en el ámbito del Consejo de Europa el debate ya no es si existe o no un derecho a disponer de la vida, sino cómo y con qué límites puede reconocerse y regularse en el marco del Convenio» (Arruego, 2019: 131).

9 No es posible entender cómo de una afirmación así — aunque el autor no cita la de Lambert sino que solo parece apoyarse al respecto en las similares de Haas, Koch y la anulada de Gross - pueda deducirse que «es perceptible cierta predilección del Tribunal por un futuro escenario de regulación de la muerte asistida» (Arruego, 2019: 133). 
Es así como la sentencia de la Gran Sala estimó en aquella ocasión, y tras un pormenorizado análisis de todas las circunstancias, que no se había violado el art. 2 de la Convención por haberse retirado la alimentación e hidratación artificiales a una persona en estado vegetativo crónico ${ }^{10}$. No obstante, cinco de los diecisiete jueces que componían el Tribunal disintieron con un voto particular de contenido bastante impresionante — que expone cómo, en realidad, a su juicio, el enfermo ni siquiera se encontraba en una situación propiamente terminal de su vida hasta días después de privarle de la nutrición e hidratación-, cuyo principal fundamento residió en considerar que no pudo tenerse por expresada la voluntad de tal opción por parte del enfermo y que la legislación francesa estaría otorgando un peso determinante a los criterios del personal médico, así como en un cuestionamiento de la calificación como «artificiales» de los modos utilizados en el caso para la alimentación e hidratación del enfermo, que, a su juicio, tendrían la naturaleza de «cuidados ordinarios» (n. $\left.{ }^{\circ} 10\right)$. Por ello, aunque se muestran de acuerdo sobre la diferencia entre «eutanasia y suicidio asistido, de una parte, y abstención terapéutica, de otra", se oponen a que lo declarado en el apdo. 141 de la sentencia refleje la realidad del caso, porque «este asunto — dicen - es un asunto de eutanasia que no quiere llamarse por su nombre» (p. 9). Lo que, en cualquier caso, reafirma implícitamente que, con toda evidencia, el criterio unánime del Tribunal fue el de justificar no forma alguna de eutanasia propiamente dicha o de suicidio asistido sino únicamente la opción en favor de la abstención terapéutica, aunque pueda haberse equivocado la mayoría en la valoración de los hechos, a la luz de lo expuesto por la minoría disidente.

\section{TERGIVERSACIÓN SORPRENDENTE DE LA JURISPRUDENCIA DEL TRIBUNAL EUROPEO DE DERECHOS HUMANOS POR EL TRIBUNAL CONSTITUCIONAL FEDERAL ALEMÁN EN SU SENTENCIA DE 26 DE FEBRERO DE 2020}

Resulta muy sorprendente que un Tribunal del prestigio acumulado por el Tribunal Constitucional Federal alemán en sus casi setenta años de funcionamiento, aunque, desde luego, otras de sus decisiones puedan haber sido ya

10 Mantiene implícitamente el mismo criterio, aunque sin llegar a pronunciarse sobre el fondo, la posterior decisión de inadmisión en el asunto Afiri y Biddarri c. Francia, de 23 de enero de 2018, aunque no genera en realidad jurisprudencia sino en materia de aplicación del régimen de admisión del art. 35 del Convenio. 
altamente discutibles, haya podido dictar una sentencia como la de 26 de febrero de 2020.

Esta insólita sentencia incluye en el derecho general del art. 2.1 de la ley fundamental al libre desarrollo de la personalidad, como expresión de la personal autonomía, un derecho a una muerte autodeterminada (Recht auf selbstbestimmtes Sterben), que estaría implicado en la libertad — que reconoce- de quitarse la vida, y que reclamaría el respeto de la sociedad y del Estado a la decisión de ponerle fin, en razón de la comprensión de cada uno de la calidad de vida y del sentido de la existencia, comprendiendo, asimismo, la libertad de solicitar y hacer uso de la ayuda de terceros para ello. Y, por entender que constituye una medida preventiva desproporcionada para garantizar el correcto ejercicio de ese derecho, declara inconstitucional y nula la penalización que contenía el art. 217.1 del Código Penal alemán de la asistencia al suicidio.

Sorprende mucho, especialmente, la quiebra del rigor, reconocido de ordinario al Tribunal de Karlsruhe, en el tratamiento que hace esta sentencia de la jurisprudencia del TEDH, por extendida que haya sido la doctrina que ha incurrido en lo mismo. Contra toda verdad, afirma en su apdo. 203 que «el reconocimiento de un derecho al suicidio y los límites aquí establecidos para su restricción están en armonía con el Convenio Europeo de Derechos Humanos». Luego, con la pretensión de dar razón de esta afirmación, en el apdo. 304 de su fundamentación, pondrá equívocamente en relación la afirmación hecha en Pretty (apdo. 61) sobre la inclusión de una autonomía personal en lo garantizado por el art. 8 de la Convención, con la cuestión planteada en el caso de si una persona que sufre una enfermedad física severa tiene derecho a un suicidio asistido, silenciando completamente cuanto se dijo en dicha sentencia, que hemos resumido más arriba, y que evidencia el criterio del Tribunal Europeo sobre que la naturaleza del derecho a la vida no incluye derecho alguno a la muerte, y menos a manos o con la asistencia de otro, así como que el ámbito de la autonomía personal en cuanto a la determinación del modo y momento de morir se refiere solamente a la aplicación o insistencia en tratamientos terapéuticos, incluyendo, por tanto, la legítima opción, con las debidas garantías, de someterse a la naturaleza, pero sin acción alguna propia o ajena intencionalmente dirigida a terminar con la vida.

Y aún más: en ese mismo apdo. 304, tras recoger la consideración del Tribunal Europeo, contenida efectivamente en el apdo. 65 de Pretty, acerca de que «nadie debería estar obligado a prolongar la vejez o estados de avanzada decrepitud física o mental en conflicto con ideas que se tengan asumidas con firmeza sobre la identidad propia y personal», omite la advertencia previa contenida en ese mismo párrafo que enmarca toda esa afirmación — «sin 
negar de ningún modo el principio de sacralidad de la vida protegida por la Convención»-y que lo dicho viene también precedido por lo que se dice en el apdo. 63, situándolo estrictamente "en el campo del tratamiento médico», en cuanto que, "como está reconocido en alguna jurisprudencia nacional, una persona puede reclamar el ejercicio de una elección de morir rehusando dar su consentimiento a un tratamiento que podría tener el efecto de prolongar su vida». Afirma, además, tras punto y seguido, como si se tratara de algo también sentado por el Tribunal en esa sentencia, que «el Estado y la sociedad deben respetar la decisión de poner fin a sufrimientos corporales y psíquicos mediante un suicidio asistido", y cita los apdos. 64 y ss. de Pretty como si tal cosa se dijese allí cuando la realidad es que ni allí ni en ninguna otra parte de esta sentencia se afirma tal cosa. Y aun todavía se añade otra afirmación, invocando la sentencia Haas, que, precisamente por hacerse justo tras atribuirse a Pretty lo que esta sentencia no dijo, también tergiversa el sentido y alcance de lo que el Tribunal dijera en esa sentencia de 2011: dando, en efecto, la impresión de que quiere confirmarse lo de que «debe respetarse la decisión de recurrir al suicidio asistido", que ya hemos dicho que de ningún modo se afirma en Haas ni en ninguna otro pronunciamiento del Tribunal Europeo, dice literalmente la sentencia alemana:

[...] en el asunto Haas $v$. Suiza, que se refiere a un demandante enfermo psíquico, el Tribunal ha pronunciado su doctrina jurisprudencial más precisa y expresa sobre que el derecho del individuo a decidir cómo y cuándo poner fin a su vida es un aspecto del derecho al respeto de su vida privada establecido en el artículo 8 del CEDH. Aunque condición previa para ello es que la persona en cuestión pueda formar una voluntad libre y actuar en consecuencia.

Y da como referencia el apdo. 51 de esa sentencia Haas.

Es verdad que esto es lo que literalmente dice ese apartado de la fundamentación de esta sentencia, pero se omite arteramente que, además de que no es verdad que al decirse eso se añadiera algo nuevo a lo ya dicho en Pretty — se evidencia, por el contrario, que es jurisprudencia derivada en último término de esta sentencia precisamente, a la que se cita en el apdo. 50-, la misma sentencia Haas se apresura a precisar en el siguiente apdo. 52 «en primer lugar que la presente causa no se refiere a la libertad de morir y la eventual impunidad de la persona que presta su ayuda a un suicidio». No es, pues, ese el tema. En Haas en modo alguno se plantea siquiera y mucho menos se decide nada sobre la legitimidad o no del suicidio asistido, como no sea, como acaba de verse, para explicitar que se trata de algo excluido de la litis. El Tribunal Europeo, en efecto, se encontró en Haas con que la legislación suiza permitía 
un cierto suicidio asistido, cuya conformidad o disconformidad con el Convenio Europeo en ningún momento se planteó, pero que no posibilitaba la consecución de ciertas sustancias letales sino con autorización facultativa, lo que llevó al señor Haas a demandar a la Confederación suiza por incluir en su legislación esa exigencia, que él consideraba que le impedía darse una muerte "digna» a la que tendría derecho conforme al art. 8 del Convenio Europeo. El Tribunal se limitó a examinar esta demanda, que desestimó por unanimidad sin considerar necesario entrar a discutir si la previsión legislativa de alguna forma de suicidio asistido es o no conforme con el Convenio, lo que, además, en ningún momento le fue planteado en ese proceso. Sorprende mucho que el Tribunal alemán pretenda encontrar en Haas apoyo alguno para extender el derecho a decidir sobre cómo y cuándo terminar con la propia vida — solo afirmado en toda la jurisprudencia del Tribunal de Estrasburgo, repetimos, en relación con la aplicación o continuidad de tratamientos terapéuticos- a cualquier forma de suicidio asistido. Se trata de un error manifiesto y grave ${ }^{11}$.

Y continúa aún el Tribunal de Karlsruhe, en esta desafortunada sentencia de 2020, distorsionando la jurisprudencia del Tribunal Europeo. En su apdo. 305 recoge lo dicho, obiter dictum, en Pretty y, luego, en Haas o Koch, sobre que, en efecto, los Estados partes de la Convención Europea tienen un significativo margen de apreciación en su deber de ponderar el derecho del individuo a su autodeterminación, del art. 8, y el deber del Estado de proteger la

11 En el que han incurrido también diversos autores ya citados u otros como Rey (2019: 33-34). Contra lo afirmado por este mismo autor citado (ibid.), menos aún puede deducirse en rigor tal cosa de la sentencia Gross c. Suiza, de 14 de mayo de 2013, de la Sala 2..$^{\text {a }}$ que simplemente declaró (y con el voto en contra de su presidente y de dos más de los otros seis magistrados) que se había producido una violación del art. 8 de la Convención por la legislación suiza por no establecer pautas claras sobre el alcance de un derecho, el de obtener una dosis de un producto letal con prescripción médica, pero sin valoración alguna sobre la conformidad o disconformidad con el Convenio de ese derecho en sí mismo. Esta sentencia, además, fue privada de valor por la de la Gran Sala sobre el mismo asunto, de 30 de septiembre de 2014 (adoptada con nueve votos a favor y ocho en contra), que declaró que la demanda debió ser inadmitida. Análogo error (sobre Haas y otras sentencias como la de Koch y Gross, 2013) en Arruego (2019: 129-130), quien cita textualmente trozos de los apdos. 54 y 57 de Haas que no se corresponden literalmente con sus afirmaciones y sin el contexto que explicita el apdo. 52, y que, en cuanto a Gross, 2013, no advierte sobre la anulación posterior de esta sentencia, aunque en nota posterior sí informa de ella pero como dando a entender que, al haberse hecho por razones formales, sus afirmaciones de fondo conservarían valor, lo que no parece sostenible. 
vida conforme al art. 2. Pero, además de que el Tribunal Europeo no reduce la debida protección de la vida a la "de terceros» — como sesgadamente da a entenderse al inicio de este apdo. 305-, omite lo que no dejó de advertir el propio Tribunal en el mismo apdo. 70 de Pretty que cita allí la sentencia alemana, y que es elemental: que la decisión de las autoridades nacionales en cualquier caso "queda sujeta a [una posible] revisión por el Tribunal en su conformidad con el Convenio [Europeo de Derechos Humanos]». La aún más fundamental sentencia posterior Lambert, de 2015, que no se entiende no sea mencionada ni tenida en cuenta por la sentencia alemana de 2020, concluye, asimismo, sus consideraciones sobre el dicho margen de apreciación con la afirmación rotunda y clara de que tal margen «no es, sin embargo, ilimitado», y que, en concreto, el Tribunal Europeo «se reserva el control del respeto por el Estado de las obligaciones que para él se desprenden del art. 2», para proteger la vida, que pueden incluir, desde luego, obligaciones de protección no solo frente a otros sino también con respecto a sí mismo, como lo evidencia, para el caso, por ejemplo, de personas residenciadas en hospitales psiquiátricos, la sentencia de la Gran Sala en el asunto Fernandes de Oliveira c. Portugal, de 31 de enero de 2019, en su apdo. 103 y concordantes.

Cita, en fin, la sentencia del Tribunal alemán lo que, en todo ese contexto, afirmó Pretty al final de su ap. 74, que «corresponde primeramente a los Estados valorar el riesgo y la probable incidencia de abuso si se relajase la general prohibición de los suicidios asistidos o se generasen excepciones». Pero la cita es, significativamente, de nuevo incompleta y omite, además, la clara advertencia que no deja de hacer esa sentencia: que «es claro que existen riesgos de abuso, a pesar de lo que se diga sobre la posibilidad de garantías y de procedimientos protectores». Nada se dirá tampoco de lo que añade la misma sentencia europea al inicio del apdo. 76, de que «por lo tanto el Tribunal no estima que la amplia naturaleza — el amplio alcance- de la prohibición del suicidio asistido sea desproporcionada», porque «no le parece arbitrario al Tribunal que la ley refleje la importancia del derecho a la vida, mediante la prohibición del suicidio asistido».

En fin, todavía, al final del mismo apdo. 305, el Tribunal de Karlsruhe vuelve a ofrecer una idea distorsionada del criterio contenido en la jurisprudencia del Tribunal Europeo, afirmando, sin mención alguna del limitado alcance con que, como venimos diciendo, en todo momento este Tribunal se ha referido a ello — solo para la opción por una posible abstención terapéutica-, que «el TEDH enfatiza, sin embargo, también, que el derecho a autodeterminar cuándo y cómo debe terminar la propia vida, no debe ser sólo teórico o aparente», citando a Haas, apdo. 59 y ss. En realidad, la cita, más que tomada, está inspirada en lo que esta sentencia dijo en el apdo. 60, donde se 
limitó a rechazar lo que argumentaba en la ocasión el demandante, afirmando simplemente para el caso — con las particularidades ya relatadas_-, que, «en consecuencia, el Tribunal no estima que el derecho del demandante a escoger [en los términos que le reconocía la legislación suiza, no cuestionados en el proceso] cuándo y cómo morir solo exista de forma teórica e ilusoria». En modo alguno estaba el Tribunal proclamando un derecho general como el que sugiere la cita que hace la sentencia alemana. En el apdo. 61, Haas es bien clara: «[...] atendiendo al margen de apreciación de que disponen en este ámbito las autoridades internas, el Tribunal estima que suponiendo incluso [la cursiva es nuestra] que los Estados tuvieran la obligación positiva de adoptar medidas que posibiliten el suicidio con dignidad, las autoridades suizas no violaron esta obligación en el presente caso». Lo dicho por el Tribunal resultó tergiversado llamativamente en la sentencia alemana.

Ya hemos hecho notar, en fin, lo extraño que resulta que el Tribunal de Karlsruhe parezca desconocer en 2020 la principal sentencia del Tribunal Europeo en la materia, la Lambert, de 2015, cuyos pronunciamientos son bien claros al respecto y evidencian la falsedad de imputar a la jurisprudencia del Tribunal Europeo un reconocimiento o incluso una posición favorable al reconocimiento de cualquier derecho al suicidio asistido.

\section{LA CUESTIÓN BAJO LA CONSTITUCIÓN ESPAÑOLA}

Cuando llevamos nuestra atención al derecho español, hay que recordar ante todo, tras cuanto va dicho, que el art. 10.2 de la Constitución española de 1978 obliga a interpretar «las normas relativas a los derechos fundamentales y a las libertades que la Constitución reconoce, de conformidad con la Declaración Universal de Derechos Humanos y los tratados y acuerdos internacionales sobre las mismas materias ratificados por España». Lo dicho por eso en el CEDH de 1950 —o sus protocolos posteriores - sobre alguno de esos derechos o libertades que la Constitución española reconoce y garantiza, el primero de los cuales - art. 15- es, sin duda, el derecho a la vida, y entre los que se cuenta, desde luego, también —art. 18- el derecho a la intimidad personal, pero asimismo - en el propio art. 15- un derecho a la integridad fisica $y$ moral (en el que nuestro Tribunal Constitucional ha identificado contenidos relevantes a nuestros efectos), no solamente tiene en Espańa la fuerza supralegal de obligar que es propia de los tratados — tal y como se desprende del art. 96 de la misma Constitución—, sino que, además, resulta determinante en la interpretación de lo garantizado por la propia Constitución, siempre que, naturalmente, se acomode a la vez a lo que, con superior relevancia por 
su universalidad, esté establecido al respecto en la Declaración Universal de 1948 y en los tratados o acuerdos internacionales de carácter universal ratificados por Espańa sobre derechos humanos. Además, en cuanto que la jurisprudencia del TEDH, del Consejo de Europa, determina el alcance y exigibilidad de lo dispuesto por el Convenio Europeo en lo que haya podido resultar dudoso, se entiende que esta jurisprudencia reviste una relevancia similar como obligada referencia hermenéutica en la interpretación de los derechos y libertades garantizados por la Constitución. Así lo viene haciendo el TC español (SSTC 303/1993, FJ 8, 119/2001, FJ 5, o 37/2011, FJ 4).

Se ha llegado a decir que, en la doctrina del TC, «la STC 120/1990 es, en esta materia el leading case» (Rey, 2019: 29), aunque es más que dudoso que merezca tan relevante reconocimiento, dadas algunas de sus ambigüedades y por el concreto y limitado objeto del proceso de amparo en que se produjo, que indudablemente condicionó sus pronunciamientos. Como es sabido, en esta sentencia el Tribunal resolvió esencialmente sobre «la licitud constitucional» de una decisión judicial que ordenó «la alimentación forzosa por vía parenteral cuando, de acuerdo con los conocimientos médicos, esa alimentación era necesaria para impedir el riesgo de muerte», por haber ya perdido la conciencia los huelguistas de hambre de que se trataba en el caso (FJ 6), internos penitenciarios pertenecientes a los GRAPO (FJ 3).

Afirma, no obstante, netamente el Constitucional, en el FJ 7 de esa sentencia, que el derecho a la vida tiene «un contenido de protección positiva que impide configurarlo como un derecho de libertad que incluya el derecho a la propia muerte», afirmación que viene a ser equivalente a la que vimos que se contiene en la sentencia Pretty del Tribunal Europeo de Derechos Humanos, doce años más tarde, nunca modificada en esa apreciación. Por lo tanto, si el derecho a la vida no comporta un derecho de libertad para elegir entre vivir o morir, ni incluye, en consecuencia, un derecho a la propia muerte, es obvio que, en esta misma medida, sí que hay un deber jurídico — exigible jurídicamente en cuanto sea razonablemente posible — de vivir, hasta tanto la misma naturaleza que le proporcionó a cada uno la vida y le permite mantenerla ponga término a esta; dicho de otro modo, hasta tanto venga la muerte por causas naturales, no provocadas ni activadas artificialmente por ninguna persona humana, incluida la misma de cuya vida se trate ${ }^{12}$.

12 Rey ha escrito, con razón, que «la doctrina del Tribunal Constitucional español es firme en este punto: el derecho a la vida no incluye la facultad de disponer de ella; la decisión de morir no está amparada por el derecho a la vida» (2019: 29), aunque luego diga que «no existe un deber jurídico de vivir» (ibid.: 28), asumiendo la discutible terminología empleada por la Sentencia 120/1990 en uno de sus tramos menos 
Aunque, al tratar de explicar su importante afirmación, el Tribunal incida, sin embargo, en algunas incoherencias desconcertantes — huella quizá de las dificultades de consenso entre los tres ponentes de la sentencia, que no logró evitar sendos votos particulares de dos magistrados-, no dejará de insistir en que «la privación de la vida propia o la aceptación de la propia muerte [...] no [es], en ningún modo, un derecho subjetivo que implique la posibilidad de movilizar el apoyo del poder público para vencer la resistencia que se oponga a la voluntad de morir, ni, mucho menos, un derecho subjetivo de carácter fundamental en el que esa posibilidad se extienda incluso frente a la resistencia del legislador, que no puede reducir el contenido esencial del derecho». Lo que se vuelve a remachar diciendo que «no es posible admitir que la Constitución garantice en su art. 15 el derecho a la propia muerte». La Constitución no ampararía, pues, en suma, derecho alguno a que los demás le dejen a uno provocarse su propia muerte o a que se la faciliten. En definitiva — se concluirá aún —, en el derecho fundamental a la vida «no se incluye el derecho a prescindir de la propia vida ${ }^{13}$.

De la vida se dice, además, en el FJ 8 de la misma sentencia, que, «en su dimensión objetiva, es "un valor superior del ordenamiento jurídico constitucional" y "supuesto ontológico sin el que los restantes derechos no tendrían existencia posible" (STC 53/1985)», por lo que su protección justificará suficientemente la restricción que a alguien se le imponga a su mismo derecho a la integridad física y moral, también garantizado por el art. 15 de la Constitución, "mediante el cual se protege la inviolabilidad de la persona», como se dice en ese mismo FJ.

Además de la STC 137/1990, que reiteró prácticamente cuanto había dicho la 120/1990, años más tarde, la STC 154/2002, en su FJ 10, recordaría lo expresado en su FJ 8 a que acabamos de referirnos, a propósito de señalar la importancia del «valor de la vida, en cuanto bien afectado por la decisión" implicada en el caso enjuiciado, como límite de otros derechos fundamentales como en concreto los de libertad religiosa y el derecho a la integridad física, ambos relevantes para el caso, advirtiendo, además, sobre la especial trascendencia de lo que puede "afectar en sentido negativo a la vida", que "tiene, como notas esenciales, la de ser definitivo y, en consecuencia, irreparable». Y, enlazándolo con ello, la misma sentencia, en su FJ 12, reitera lo dicho en su FJ 7 por la 120/1990 sobre que «el derecho fundamental a la vida tiene "un

claros, donde parece afirmar que pueda hablarse en el orden jurídico de una libertad que no sea un derecho subjetivo.

13 Aunque tal afirmación se haga en concreto con respecto al problema específico del caso relativo a la Administración penitenciaria. 
contenido de protección positiva que impide configurarlo como un derecho de libertad que incluya el derecho a la propia muerte" ${ }^{14}$.

Con razón se ha llegado, por todo ello, a afirmar:

[...] leídas conjuntamente las jurisprudencias del Tribunal Constitucional español y del Tribunal Europeo de Derechos Humanos [...], la conclusión que se ofrece al intérprete parece clara: las disposiciones que en la Constitución española (art. 15) y en el Convenio de Roma (art. 2) aluden a la protección jurídica de la vida no amparan el derecho a disponer de ella. Reconocer como derecho fundamental la eutanasia activa o al suicidio asistido requeriría, por tanto, una reforma constitucional expresa en ese sentido (Rey, 2019: 34).

Aunque, desde luego, no puedan reconocerse con el rango de derechos fundamentales o como parte del contenido legítimo de alguno de estos, ¿podrían ser de algún modo actuaciones constitucionalmente admisibles? Tendrían, desde luego, para ello que respetar los propios derechos fundamentales y los deberes que la Constitución impone a los poderes públicos con respecto a ellos.

$\mathrm{Y}$ a estos efectos, en la perspectiva que impone el art. 10.2 de la Constitución, será importante tener en cuenta, como ya recordamos, que los derechos fundamentales a la vida y a la integridad física y moral de su art. 15, a la libertad personal del 17 o al derecho a la intimidad personal del 18 , vienen conformados, en ciertos aspectos de su alcance, por la jurisprudencia del TEDH en la interpretación que ha venido haciendo de los arts. 2 y 8 del Convenio Europeo de 1950, en los términos expuestos.

En este sentido, parece incontestable que debe concluirse que ninguno de los derechos fundamentales mencionados puede amparar una autonomía o autodeterminación personal que incluya eliminar la propia vida — sin la cual desaparecen todos los derechos- y menos aún por la acción positivamente letal de un tercero o con su ayuda, y que estas conductas son contrarias al deber de protección de la vida de cualquiera, que recae sobre los Estados, a los que corresponde asegurarla del modo que estimen más razonable y proporcionado, sin perjuicio de lo que finalmente pueda juzgar el TEDH.

14 Aunque luego deduzca de ello para el caso algo incomprensible en buena lógica, en lo que no necesitamos entrar ahora, pero que supondría algo tan difícilmente entendible como que una conducta que se niega como contenido de una libertad y del correspondiente derecho se afirme a la vez como expresión del «principio general de libertad» supuestamente legítimo. 
Como muchas veces se ha también señalado, la apertura legislativa a la legitimidad del suicidio asistido y la eutanasia proporciona, además, una lamentable excusa a la denegación a muchas personas de los remedios proporcionados y de los cuidados paliativos que hay que entender que les son debidos en virtud del derecho a la protección a la salud proclamado por el art. 43 de la Constitución e incluso del derecho a la integridad fisica y moral ya mencionado ${ }^{15}$.

Por lo demás, admitir la asistencia al suicidio o la eutanasia de personas que se encuentren en condiciones de vida física o psíquica especialmente degradadas ya constituiría una violación inaceptable del principio de igualdad que la Constitución española proclama destacadamente en sus arts. 1.1 y 14 , pero ello sería, además, tanto más grave cuanto esta misma ley fundamental obliga específicamente en su art. 49 a amparar especialmente a los que denomina — con terminología aceptada hace cuarenta años- disminuidos físicos, sensoriales y psíquicos sensoriales, para el disfrute de los derechos que su título I otorga a todos los ciudadanos, y en su art. 50 impone a los poderes públicos el deber de promover el bienestar en particular de los ciudadanos durante la tercera edad, mediante un sistema de servicios sociales que atenderán sus problemas especificos de salud.

\section{PRONUNCIAMIENTOS CLAROS DEL TRIBUNAL SUPREMO NORTEAMERICANO}

El 26 de junio de 1997, hace ahora poco más de veintitrés años, el Tribunal Supremo de los Estados Unidos de América pronunció dos importantes sentencias en los asuntos del estado de Washington et al. v. Glucksberg et al. (521 U. S. 702 [1997]), y del estado de Nueva York, a través de su abogado general Vacco, et al. v. Quill et al. (521 U. S. 793 [1997]). En una y

15 Resulta particularmente ilustrativa la intervención de Antonio Filipe en la Asamblea de la República de Portugal, el 21 de febrero de 2020, en nombre del Partido Comunista Portugués (PCP), en la que, entre otras cosas, dijo: «[...] num País em que os cuidados paliativos só são acessíveis a $25 \%$ da população, e certamente que entre esses $25 \%$ não estarão os cidadáos menos favorecidos, qual é a liberdade que se oferece aos outros $75 \%$ ? [...] um País não pode criar instrumentos legais para ajudar a morrer quando não garante condiçôes materiais para ajudar a viver. Um País que se quer decente náo pode condenar cidadáos a ter de optar entre o sofrimento ou a morte» (Diário da Assembleia de República, I Série, n. ${ }^{\circ} 32$, p. 14). Véase también De la Torre (2019: 23-25). 
otra, por unanimidad, aunque cuatro de los nueve magistrados discreparan de alguno de los razonamientos expuestos por el presidente Rehnquist como ponente $^{16}$, el alto Tribunal dio la razón a los tribunales federales de distrito y revocó lo decidido por los tribunales de apelación de los circuitos, respectivamente, 2. ${ }^{\circ}$ (con sede en la Ciudad de Nueva York) y 9. (con sede en San Francisco). Distinguiéndolo de la decisión de retirar o no continuar un tratamiento terapéutico, rechazó el Tribunal que prohibir y penalizar el suicidio asistido sea contrario a la Constitución americana, fuera por lesionar una libertad o derecho protegido por la Due Process Clause de la 14. ${ }^{\mathrm{a}}$ enmienda, como razonará en la primera de ambas sentencias, fuese por contrario a la Equal Protection Clause de la misma 14. a enmienda, como explicará en la segunda.

La 14. ${ }^{\mathrm{a}}$ enmienda ha tenido y tiene particular importancia, como se sabe, en el orden constitucional americano y para la unidad jurídica de la nación ${ }^{17}$, especialmente por su sección $1 .^{a}$ en la que prohíbe que cualquiera de los estados de la Unión pueda privar a cualquier persona de su vida, libertad o propiedad sin el debido procedimiento legal, o denegarle, dentro de su jurisdicción, igual protección de sus leyes.

Pues bien, en Glucksberg se rechazó que un supuesto derecho a cometer suicidio que incluya un derecho a ser asistido para hacerlo tenga «algún lugar en las tradiciones de la Nación americana, dado el rechazo continuo y firme del país, casi universal, de tal derecho, incluso para enfermos terminales, adultos y en posesión de sus facultades mentales. Para admitirlo — dijo el Tribunal — tendría que revertir siglos de doctrina y práctica jurídicas, y echar abajo las opciones políticas de casi todos los estados de la Unión» (Syllabus, b).

Precisó, además:

16 A su opinion se adhirieron en las dos sentencias Scalia, Kennedy, Thomas y Sandra Day O'Connor, aunque esta formuló a la vez un voto concurrente complementario al que se adhirieron en parte Ruth B. Ginsburg y Stephen G. Breyer. Este, además, presentó por su parte otro voto concurrente, lo mismo que, más por extenso, hicieron Stevens y, sobre todo, Souter, cuya opinion concurrente en Glucksberg ocupó las pp. 752 a 789 de su publicación oficial y añadió otra más breve en Vacco para apenas explicar por qué se unía al fallo de la sentencia aunque estimase que la cuestión merecía más atenta consideración.

17 Tras la guerra civil (1861-1865), fue propuesta en junio de 1866 y ratificada el 9 de julio de 1868, durante la Presidencia del demócrata Andrew Johnson, iniciada un mes antes del fin de la guerra, el 15 de abril de 1865, con la muerte de Lincoln, con quien había sido elegido vicepresidente en noviembre de 1864, dentro de la excepcional Unión Nacional establecida durante la guerra. 
[...] el derecho, protegido constitucionalmente, a rehusar una vital hidratación o nutrición, tal como fue tratado por el Tribunal en alguna sentencia anterior $\left(\right.$ Cruzan $\left.^{18}\right)$, no fue simplemente deducido de abstractos conceptos sobre la autonomía personal, sino fundado, por el contrario, en la historia y tradiciones de la Nación, dada la regla del common law de que la medicación forzada era maltrato y la larga tradición de proteger la decisión de rehusar un tratamiento médico no querido ${ }^{19}$.

Y, en fin, que, «aunque en Casey $^{20}$ se había reconocido que muchos de los derechos y libertades protegidos por la Due Process Clause tienen que ver con la autonomía personal, de ello no se sigue — nótese bien — que todas y cada una de las importantes, íntimas y personales decisiones personales estén protegidas por ella» (Syllabus, b). Por lo demás, como legítimos intereses públicos que tienen relación con la prohibición del suicidio asistido, el Tribunal menciona en la misma sentencia y justifica los de

[...] prohibir el matar intencionalmente y preservar la vida humana; prevenir el serio problema público sanitario del suicidio, especialmente entre los jóvenes, ancianos y los que sufren dolores irremediables o depresión u otros desórdenes

18 Cruzan v. Director, Missouri Dept. of Health, 497 U. S. 261, de 25 de junio de 1990. Por cinco a cuatro, el Tribunal entendió conforme a la Constitución americana que Missouri exigiera pruebas particularmente exigentes para que los padres pudieran sustituir a un hijo incapaz en la expresión de su voluntad de oponerse al mantenimiento artificial de su vida. La opinion mayoritaria fue redactada también por el presidente Rehnquist.

19 Con más detenimiento, la opinion mayoritaria señaló, remitiendo a lo dicho en Vacco, que «la decisión de cometer suicidio con ayuda de otro puede ser, desde luego, tan personal y profunda como la de rehusar un tratamiento médico no querido, pero nunca ha disfrutado de similar protección legal. Ciertamente los dos actos son amplia y razonablemente contemplados como muy distintos», y ańadió que "en la misma decisión Cruzan [...] no dimos indicio alguno de que el derecho a rehusar un tratamiento médico no querido pueda ser de algún modo transmutado en un derecho a la ayuda en la comisión de suicidio. 497 U. S. 280» (521 U. S. 725-726). Y más abajo: "La historia del tratamiento jurídico del suicidio asistido en este país ha sido y sigue siendo la del rechazo de casi todos los esfuerzos para permitirlo. Siendo tal el caso, nuestras decisiones nos llevan a concluir que el pretendido "derecho" a ayuda para cometer suicidio no es una libertad fundamental protegida por la Cláusula del Debido Procedimiento» (521 U. S. 728).

20 Planned Parenthood of Southeastern Pennsylvania v. Casey, 505 U. S. 833, de 29 de junio de 1992. 
mentales; proteger la integridad ética de la profesión médica y mantener el oficio de los médicos en curar a sus pacientes; proteger a las personas pobres, ancianas o con discapacidades, enfermos terminales y personas de otros grupos vulnerables, de toda indiferencia, prejuicio y presión psicológica o económica para poner fin a sus vidas; y evitar un posible deslizamiento hacia la eutanasia voluntaria y quizás incluso la involuntaria ${ }^{21}$. El peso relativo de estos diversos intereses no tiene por qué ser valorado de manera exacta, pero son incuestionablemente importantes y legítimos, y la ley de que se trata está cuando menos razonablemente relacionada con su promoción y protección (Syllabus, c, desarrollado en pp. 728-735 de la opinion mayoritaria).

De los votos concurrentes vale la pena, por lo demás, retener aquí lo dicho por el juez Stevens —a pesar de su posición finalmente contradictoria_- ${ }^{22}$ :

Hay algo de verdad en la observación de John Donne de que «Ningún hombre es una isla». El Estado tiene interés en preservar y promover los beneficios que todo ser humano puede brindar a la comunidad, una comunidad que prospera con el intercambio de ideas, expresiones de afecto, recuerdos compartidos e incidentes divertidos, lo mismo que con las aportaciones materiales que sus miembros generan y sostienen. El valor para los demás de la vida de una persona es demasiado precioso para permitirle al individuo reclamar un derecho constitucional a una autonomía completa para tomar la decisión de poner fin a esa vida (521 U. S. [1997], p. 741) ${ }^{23}$.

No menos trascendental ha sido en la historia jurídica norteamericana contemporánea la Equal Protection Clause. En Vacco se decidió que la

21 La opinion mayoritaria transcribió espeluznantes datos de la práctica, ya por entonces, de la eutanasia en los Países Bajos, extraídos de un estudio del propio Gobierno holandés (521 U. S. 734).

22 Abierta a admitir el suicidio con asistencia médica en circunstancias particulares, con tan discutibles argumentos, deducidos de la jurisprudencia sobre la pena de muerte, como que «un estado tiene el poder de asignar un valor menor a algunas vidas que a otras; no hay una exigencia absoluta de que un estado trate a toda vida humana como si tuviera el mismo derecho a ser preservada» (521 U. S. [1997], p. 738) o que "la sacralidad de la vida humana no exige que sea siempre preservada» (521 U. S. [1997], p. 741). Sabido es que, nombrado por Gerald Ford en 1975, John Paul Stevens fue evolucionando hacia posiciones «progresistas» hasta dejar el Tribunal en 2010.

23 El argumento se encuentra ya en Tomás de Aquino (1274), qu. 64, art. 5, 2. a razón del respondeo, y apuntado en Aristóteles (2005: 179, libro V, capítulo 11). 
penalización del suicidio asistido del estado de Nueva York, que incluiría la autoadministración de fármacos necesitados de receta médica por parte de enfermos terminales en ejercicio de sus facultades mentales, pero no la retirada, al mismo tipo de personas, de sistemas de mantenimiento artificial de la vida, no es contraria a dicha cláusula constitucional, que «obliga a los estados a tratar igual los casos iguales pero les permite tratar de forma desigual los casos distintos». Cuando "la ley de Nueva York pone fuera de la ley el suicidio asistido, ni infringe derechos fundamentales ni lleva a cabo distinciones sospechosas, y es acreedora en consecuencia de una sólida presunción de validez»; «no se hacen distinciones personales» $\mathrm{y}$ "la distinción entre dejar morir a un paciente y hacer que este paciente muera es importante, lógica, racional y bien establecida» $\mathrm{y}$ «ha sido ampliamente reconocida y asumida en la profesión médica, por los tribunales estatales y la abrumadora mayoría de las legislaturas de los estados, que, como la de Nueva York, permiten lo primero mientras prohíben lo último" (Syllabus, a, en 521 U. S. 794, y pp. 799-808 de la opinion mayoritaria).

En fin, los mismos «intereses» o razones de interés público o general que se dijo en Glucksberg que justificarían la regulación penalizadora del suicidio asistido en cuanto pudiera requerir la cláusula del debido procedimiento se enuncian también ahora como legitimadores del distinto trato dado por la ley a los dos diferentes tipos de actuaciones y conductas de que se trata, con pleno respeto de la cláusula de protección de la igualdad (Syllabus, b, y pp. 808-809 de la opinion mayoritaria).

En verdad el Tribunal Supremo no ha modificado estos criterios en su sentencia Gonzalez v. Oregon, del 17 de enero de $2006^{24}$, en la que consideró inválida una disposición interpretativa del fiscal general de los Estados Unidos que prohibió a los médicos prescribir drogas reguladas por la federal CSA (Controlled Substances Act o Ley de Sustancias Controladas) de 1970, en caso de suicidio médicamente asistido como el permitido por una ley de Oregón de 1994, confirmada en octubre de 1997 (Oregon Death with Dignity Act, $O D W D A)^{25}$, por entender que no entraba en los fines médicos legítimos con

24546 U. S. 243. Adoptada por una mayoría de seis contra tres, por el mismo Tribunal de las sentencias de 1997, en el que solamente Renhquist — nombrado por Nixon en 1972 - había sido sustituido en 2005 por el nuevo presidente John G. Roberts —nombrado por Bush jr.—, que sigue presidiéndolo actualmente, y que votó en contra junto con Scalia y Thomas. La opinion mayoritaria fue elaborada por Anthony Kennedy y respaldada por Stevens, Sandra O'Connor, Souter, Ruth Ginsburg y Breyer.

25 Suele darse como fecha de aprobación de esta ley el 27 de octubre de 1997, aunque parece que recibió una primera aprobación ya en 1994, tal y como se indica en la opinion del juez Kennedy. 
los que un médico ha de prescribir esas sustancias. La sentencia no entró a valorar la constitucionalidad de esta práctica, sino que se limitó a decidir una cuestión competencial: que la regulación de lo que entra o no en la legítima actuación de los médicos es competencia de los estados federados y no era objeto de la citada CSA federal. Esta, por tanto, no ampararía, a su juicio, por esa razón competencial, la disposición administrativa de que se trataba y menos sin que hubiera intervenido en ella el secretario de Salud y Servicios Humanos del Gobierno federal, ya que de lo que se ocupa la CSA es del tratamiento y consumo ilícito de drogas y solo en ese contexto aludiría a las eventuales prescripciones médicas. Sin perjuicio, desde luego, de las buenas razones que aportaron Scalia y Thomas en sus votos particulares para discrepar de lo decidido, entendiendo justificada la disposición administrativa enjuiciada, y propio de la competencia federal determinar lo que es o no un legitimate legal purpose en la dispensación de sustancias controladas como drogas. Pero lo discutido se centró y se limitó, en cualquier caso, a la interpretación de lo que la autoridad gubernativa o administrativa federal, en el marco del reparto competencial entre los estados y la Unión, podía o no hacer, dados los términos de la ley federal en cuestión. A pesar de toda la trascendencia sustantiva del suicidio asistido, no fue en puridad objeto de discusión y menos de decisión ${ }^{26}$.

\section{TRES CONSIDERACIONES CENTRALES A MODO DE CONCLUSIÓN}

Hemos visto que, aunque en algunos muy pocos países en el mundo, y aun por parte de algún Tribunal del prestigio acumulado del Bundesverfassunggericht de la República Federal de Alemania, se haya dado el lamentable paso

26 Por más que, en efecto, en la opinion de Scalia se recuerde lo indicado en el memorándum que figuraba como apéndice de la directiva cuestionada del fiscal general: que «virtualmente toda la doctrina médica autorizada desde Hipócrates a la actual Asociación Médica Americana (AMA) confirma que el suicidio asistido raramente o nunca ha sido visto como una forma de "prevenir, curar o aliviar" la enfermedad y — más aún- que el suicidio asistido no forma parte "legítima" de esta "ciencia o arte" "; ańadiendo que, "ciertamente, la AMA tiene determinado que "el suicidio medicamente asistido es fundamentalmente incompatible con la función propia del médico como sanador" ", lo que también se recuerda que fue asumido por el Tribunal en Glucksberg, de cuya sentencia reproduce otro bien expresivo texto, remitiendo aún a otros más.

Un comentario amplio sobre este asunto y la ley de Oregón implicada, en Medina Morales (2013, particularmente p. 405 y ss.). 
de legitimar la ayuda al suicidio o incluso, en su caso, la eutanasia directa por un tercero, ni el TEDH, ni el TS de los EE. UU. de América, ni el TC español se han pronunciado nunca a favor de la legitimidad de que alguien pueda matar a otro que lo quiera o ayudarle a matarse, afirmando, en cambio, la ausencia de un derecho a morir o una libertad para morir, la necesidad del respeto a toda vida humana, el deber del Estado de no atentar contra la vida y de protegerla, y también que la autonomía propia de la libertad personal puede alcanzar a la decisión, tomada en el ejercicio verdaderamente voluntario de las facultades mentales, de no recibir o no prolongar determinados tratamientos médicos o de mantenimiento artificial de la propia vida —aunque esto último sigue planteando un problema definitorio de sus límites- que impliquen obstinación terapéutica desproporcionada, con independencia, en fin, de la insistencia en la necesidad de incluir los necesarios cuidados paliativos en el derecho a la asistencia sanitaria.

Abandonar estos criterios o pretender dar el paso de añadir la posibilidad de que el Estado ampare lo que podría pasar a ser considerado como un derecho a ser objeto de una acción letal de un tercero o de uno mismo, con ayuda de otro, y más especialmente de personal facultativo, en determinadas circunstancias de sufrimientos físicos, psicológicos o morales que estarían haciendo una vida "indigna» de ser vivida, y como medio cabalmente —el único posible de hecho o el más efectivo- de acabar con ellos, plantea tres cuestiones a las que, para concluir, nos referiremos sucintamente:

\section{1. ${ }^{a} \quad$ ¿Comprende la libertad humana, la autonomía personal de la persona} humana, inherente a su dignidad de tal persona, la posibilidad de suprimirla, de renunciar a ella definitivamente, mediante la supresión de la vida en que se sustenta?

Ciertas corrientes se vienen dejando sentir en el sentido de una respuesta positiva a tal pregunta, abriendo el camino a la legitimidad ética y jurídica del suicidio, sin o con asistencia o la colaboración de terceros. Aunque por lo general los que se decantan por esta posición no dejan de incluir ciertas condiciones, no solo en garantía de la efectiva libertad o autonomía de quien ha de tomar tal decisión —en la medida, claro está, en que ello es posible-, sino también eventualmente en razón de obligaciones con otras personas o con la sociedad a las que no cabría sustraerse por ese medio en perjuicio de quienes con ello resultarían afectados, o también porque restringen esa suprema disponibilidad a determinados supuestos de lo que de un modo u otro vienen a considerar «vida indigna», con cuanto ello implica de inaceptable 
discriminación, obviamente, entre vidas y vidas a efectos tan relevantes. La vinculación necesaria así entre tal derecho a poner fin a la propia vida como expresión de la autonomía personal y las supuestas condiciones de una «vida indigna» de ser vivida o de un supuesto «derecho a no sufrir» no solo evidencia las contradicciones del planteamiento ${ }^{27}$ sino su profunda incompatibilidad con el respeto exigible para toda vida humana.

No parece que quienes sostienen tales posiciones admitan hoy la posibilidad de que una persona renuncie a su libertad y autonomía de otra manera también plena, pero menos radical — en cuanto que, por lo pronto, admitiría a la postre recuperación o reversión-, cual sería la sumisión voluntaria a esclavitud.

Que la libre disposición sobre uno mismo y lo que le afecte ha de tener límites, además de lo que implica ese rechazo generalizado, y que no parece excepcionable, a la esclavitud, está en su propia naturaleza y en la naturaleza del ser humano. La libre autonomía personal permite disponer sobre cuanto puede tener razón de medio o instrumento para alcanzar nuestros fines como personas -empezando, naturalmente, por el empleo y aplicación de las propias energías, aptitudes y facultades espirituales y corporales y su pertinente cultivo y conservación-, pero no parece que pueda incluir como objeto de sus decisiones autónomas el soporte mismo y la expresión básica de nuestra condición personal, aquello que sustenta esa misma libertad, que no es en rigor un medio entre otros, sino la condición misma de poder elegir entre medios $^{28}$. La persona humana ostenta una dignidad específica por el simple

27 Como, comentando la jurisprudencia del Tribunal Constitucional colombiano, se ha advertido en la doctrina (Tomás-Valiente, 2019: 309-311, 315-318 y ss.), aun sin dejar por ello lamentablemente de defenderse un «derecho de los ciudadanos a recibir ayuda para adelantar su muerte cuando libremente así lo decidan en contextos de grave enfermedad o discapacidad o intensos sufrimientos» (ibid:: 305), lo que, a la postre, aun con limitaciones laudables — mas de dudosa eficacia, si se admiten sus presupuestos-, no deja de incurrir en una parte de la contradicción que con razón se observa críticamente en la evolución de esa jurisprudencia (ibid:: 323), ofreciéndose incluso una «solución» para acabar con las vidas de los que carecen del uso de sus facultades mentales o de comunicación (ibid:: 325), con la terrible perspectiva de una colectividad seńora de vidas y muertes, inicialmente en supuestos muy limitados, pero sin ninguna seguridad contra su progresivo ensanchamiento.

28 Ha habido, sin embargo, quien, no poco sorprendentemente, ha afirmado, con respecto al derecho a la vida, que «la obviedad de que sin existencia no hay soporte individual de derechos ha sido impropiamente utilizada para atribuirle una posición única en el catálogo de derechos fundamentales con reflejo inmediato en su interpretación», reconociendo que eso sería lo que han hecho el Tribunal Constitucional español o el Tribunal Europeo de Derechos Humanos (Arruego, 2019: 124). 
hecho de ser tal ${ }^{29}$, y en ella se enraíza su natural poder de decidir libremente su conducta optando voluntariamente entre posibilidades y medios distintos ${ }^{30}$; es por ello sujeto y nunca puede o deber ser mero objeto ${ }^{31}$; y lo es siempre, aunque se den circunstancias que limiten o impidan su natural poder de decidir libremente. Y ese no ser ni poder ser objeto no se aplica solo a las decisiones de otros sujetos, de otras personas, sobre sí, sino también a las propias

29 En España han justificado por extenso esta comprensión ontológica del término «juridificado» de la dignidad de la persona humana, destacadamente, González Pérez (1986: particularmente, p. 24) y Prieto Álvarez (2005: 158, 164 y ss.). El prof. González Pérez vuelve a remachar su concepto con toda claridad en el prólogo a esta obra de Prieto.

30 "La dignidad es un valor espiritual y moral inherente a la persona, que se manifiesta singularmente en la autodeterminación consciente y responsable de la propia vida y que lleva consigo la pretensión al respeto por parte de los demás», dijo la STC 53/1985, del 11 de abril, en su FJ 8. Nótese bien, pues, que la dignidad, según esta formulación, y como decimos en el texto, no se identifica con la autodeterminación, aunque en ella "se manifieste singularmente», no necesaria ni exclusivamente. Otra cosa es que el Tribunal haya sido coherente con esa definición, o la haya entendido del mejor modo. Es muy común no reparar en aquella fundamental diferencia entre dignidad, como cualidad esencial a toda persona humana, y la autodeterminación que es característica y exigencia natural de esta pero que puede faltar en las primeras etapas del progresivo desarrollo de la vida humana o por causas de discapacidad, enfermedad o decrepitud, sin que por ello falte la dignidad inherente a todo ser humano. Así, entre otros, Tomás-Valiente (2014: 180 y ss.). Hace años Serna (1999: 139-196) mostró bien el poco sólido uso que se ha hecho de la noción en la jurisprudencia constitucional española y no ha dejado de rondar la importancia de esa diferencia, sobre todo por sus acertados planteamientos ontológicos sobre la dignidad personal ya desde 1995. Y aunque a veces parece identificarla (en Serna, 1999) con lo que, sin embargo, criticará como concepto kantiano de autodeterminación, no deja de distanciarla de él. Después, del bien informado y completo estudio posterior (Serna, 2005: 13-77) sobre el tratamiento del concepto a la postre en la Carta de los Derechos Fundamentales de la Unión Europea, cuyo título I está dedicado precisamente a la dignidad, quizá interese destacar su observación de que la opción europea «ha sido vincular la dignidad a aquellos derechos fundamentales que prohíben prácticas identificables como reducciones de la persona a la mera condición de objeto" (p. 71).

31 Suele ser común (así, Prieto Álvarez, 2005: 169) vincular esta apreciación a Kant, que, en efecto, la formula como principio y fundamento práctico supremo (1942: 77-79), aunque me parece que está enraizada en una bastante más antigua concepción de la cultura europea, particularmente en la jurídica. 
en lo que se refiere a la propia condición personal ${ }^{32}$ : nadie puede disponer sobre sí mismo, sobre su condición personal, sobre el soporte vital de su libertad conformado por la naturaleza de manera completamente ajena a la propia intervención ${ }^{33}$, porque de ser así se estaría cosificando el propio ser personal, haciéndolo objeto de disponibilidad propia o ajena, lo que, obviamente, choca frontalmente con la dignidad humana. Nadie ha decidido ni podrá nunca decidir sobre el inicio de su propia vida ni consiguientemente sobre su condición y conformación personal —aunque tampoco nadie debe, por cierto, poder arrogarse el poder de determinarlo como si de una cosa industrial o incluso de un ser puramente vegetal o animal se tratara-, ni tampoco, en lo esencial, sobre su crecimiento y desarrollo en lo que viene determinado por la naturaleza. La vida es, sobre todo, un hecho, aunque a la vez sea objeto del más personal de los derechos y, también, de un deber, como denota el instinto natural de conservación, y la percepción, asimismo, de tantos vínculos como nos unen socialmente en solidaridad. Somos vida y personas sin intervención alguna inicial de nuestra voluntad, de nuestra libertad, y no tenemos tampoco libertad para dejar de serlo por decisión propia. Es verdad que de hecho "podemos» hacerlo en el orden puramente fáctico, pero algo especialmente trascendental rompemos con ello al rechazar abruptamente lo que somos y cómo hemos sido o estamos siendo conformados. Además de las implicaciones sociales que puedan defraudarse, quien toma esa decisión - tantas veces, cierto es, por encontrarse objetiva o subjetivamente en una situación que se llega a considerar, bajo ciertos patrones, «invivible», y no pocas veces por fallos precisamente en la solidaridad, en el cuidado posible o debido de otros - rechaza la condición en que ha sido hecho, lo que la sustenta, o, al menos, en el modo en que se viene expresando, y con ello su propia dignidad, para acabar con ella. Quien ataca de manera irreversible la propia dignidad inherente a todo ser humano precisamente para suprimirla comete algo que no puede ser sino indigno. No puede ser digno del ser humano acabar con la dignidad que le es inherente, ni puede ser un ejer-

32 «Todos los seres racionales están sujetos a la ley de que cada uno de ellos debe tratarse a sí mismo y tratar a todos los demás, nunca como simple medio, sino siempre al mismo tiempo como fin en sí mismo» (Kant, 1942: 86; la cursiva está en la versión utilizada). Vid. también, con otra tr. esp., Prieto Álvarez (2005: 169).

33 Es interesante observar que también Kant consideró relevante al respecto que los humanos forman parte de «los seres cuya existencia no descansa en nuestra voluntad, sino en la naturaleza» que es la que «los distingue ya como fines en sí mismos, es decir, como algo que no puede ser usado meramente como medio» (1942: 78). Vid. también Prieto Álvarez (2005: 169). 
cicio legítimo o lícito de la propia libertad acabar con ella. Nada, pues, puede justificar el suicidio.

Si fuera digno quitarse la vida, y con ella la dignidad, podría entenderse, además, que, como algunos pretenden, hay vidas que dejan de ser dignas, lo que hace digno eliminarlas. Y esto constituye una valoración que desconoce algo fundamental en la actual cultura de los derechos humanos proclamada en la Declaración Universal de 1948 y en tantos textos como la han seguido: «[...] que la libertad, la justicia y la paz en el mundo tienen por base el reconocimiento de la dignidad intrínseca [...] de todos los miembros de la familia humana».

Aunque, como indica el lenguaje corriente y con independencia de los usos que puedan hacerse o haberse hecho del término a efectos jurídicos (Tomás-Valiente, 2014: 167-208), haya grados accidentales diversos de dignidad que derivarán de la conducta de cada uno y de su reconocimiento social, hay una dignidad intrínseca a todo ser humano, inherente a su condición de persona, que fundamenta todos los derechos humanos ${ }^{34}$, que por nada se pierde, y que es lo que da su dignidad esencial a toda vida humana sin excepción, sin que esta pueda depender, por tanto, de valoraciones subjetivas, ni siquiera de cada uno de los que la poseen con respecto a su vida misma ${ }^{35}$. Rechazar o desconocer esto, obrar en contra de esto, es lo que es indigno de un ser humano y hasta el punto nada menos que de suprimir su dignidad

34 El TC español ha podido afirmar así en su STC 236/2007, de 7 de noviembre, FJ 3, que «todos los derechos fundamentales, por su misma naturaleza, están vinculados a la dignidad humana», que, además, «obliga a reconocer a cualquier persona, independientemente de la situación en que se encuentre, aquellos derechos o contenidos de los mismos imprescindibles para garantizarla, erigiéndose así la dignidad en un mínimo invulnerable que por imperativo constitucional se impone a todos los poderes, incluido el legislador». Entre tales derechos «inherentes a la dignidad de la persona humana (STC 91/2000, de 30 de marzo, FJ 7)» el Tribunal ha incluido en primer término, junto con otros, el derecho a la vida y a la integridad física y moral, o la libertad ideológica. Unas certeras observaciones sobre todo esto en Serna (1999: particularmente, 145 y ss.; 2005).

La fundamentación de los derechos humanos en la «intangible» dignidad del ser humano es muy explícita en el art. 1 de la ley fundamental de Alemania, como ha glosado, entre otros, Oehling (2011).

35 "[...] la dignidad ha de permanecer inalterada cualquiera que sea la situación en que la persona se encuentre... constituyendo, en consecuencia, un mínimum invulnerable que todo estatuto jurídico debe asegurar [STC 120/1990, FJ 4; también STC 57/1994, de 28 de febrero, FJ 3 a)]» (SSTC 91/2000, FJ 7, y 236/2007, FJ 3). 
esencial, al suprimir la misma existencia que posee ese carácter esencial ${ }^{36}$. ¿Cómo no se estaría violando a la vez el básico principio de igualdad que luce en la Constitución espańola en los arts. $10^{\circ}$ y 14 , destacadamente - sin que sea necesario recordar ahora en pormenor la importancia de su proclamación y garantía en la Declaración Universal y en los pactos y convenciones o tratados internacionales sobre derechos humanos-, y que ha de aplicarse principalmente, como es lógico, a los derechos fundamentales, el primero de los cuales es el de la vida?

Como se ha afirmado inteligentemente (Prieto Álvarez, 2017: 205), no dejaría de ser aplicable aquí lo que el art. 30 de la propia Declaración Universal de Derechos Humanos, aun pensando seguramente en otro tipo de actuaciones, afirma con contundencia a modo de cierre de su insigne texto: «Nada en la presente Declaración podrá interpretarse en el sentido de que confiere derecho alguno al Estado, a un grupo o a una persona, para emprender y desarrollar actividades o realizar actos tendientes a la supresión de cualquiera de los derechos y libertades proclamados en esta Declaración». Reiterando esta pauta, el art. 17 del Convenio Europeo de Derechos Humanos, como otros textos internacionales, ha dispuesto también que «ninguna de las disposiciones del presente Convenio podrá ser interpretada en el sentido de implicar para un Estado, grupo o individuo, un derecho cualquiera a [...] realizar un acto tendente a la destrucción de los derechos o libertades reconocidos en el presente Convenio [...]»37.

Solo por lapsus puede entenderse, en fin, que alguien pueda escribir sin más en la segunda mitad de la pasada década que «los sistemas jurídicos

36 En el mismo sentido González Pérez (2017: 215). En los términos expuestos, «la conexión vida/dignidad humana» en modo alguno «altera la comprensión del derecho a la vida como garante de la existencia física del individuo», lo que, sin embargo, sí ocurrirá, en efecto, si se utiliza una acepción de la dignidad humana distinta, como hace Arruego (2019: 125). Sobre la incidencia en la evolución de la jurisprudencia de la Corte Constitucional colombiana sobre eutanasia, de la «utilización [...] muy poco clara del siempre lábil y maleable concepto de dignidad", cuando tal cosa se acepta, véase Tomás-Valiente (2019: 304 y 315 a 318 y ss.).

37 Ante la ausencia de lógica para tratar de fundar en el derecho a la vida o en el derecho a la autonomía personal, o en cualquier otro derecho fundamental, la legitimidad de decidir la propia muerte y más aún de quitarse la vida con la ayuda o por la acción de otro, hay quien, para abrir camino a toda costa a lo que parece desearse, con una comprensión antropológica poco aceptable y sin criba de rigor jurídico alguna, quiere entrever el «nacimiento de un derecho de nuevo cuńo que puede rastrearse fragmentariamente en valores, principios y derechos» y de cuya fundamentación racional nada en realidad se nos dice (Arruego, 2019: 134). 
occidentales reconocen al individuo la capacidad de decidir el final de la propia existencia con base en su derecho a la libre autodeterminación, salvando su tensión con el derecho a la vida a través de la prevalencia de una voluntad consciente y madura de su titular que tendría que ser comprobada mediante medios fehacientes» (Cañamares, 2016: 353). Quizá, de acuerdo con lo previamente afirmado en el mismo estudio en que se dice tal $\cos ^{38}$, quiso decirse eso de los muy pocos sistemas jurídicos occidentales que, muy excepcionalmente, lo admiten y con no pocas restricciones (Canadá, Colombia - en una situación confusa y peculiar-, Holanda, Bélgica, Luxemburgo y Suiza), aunque hoy, tras la sentencia que hemos analizado de su Tribunal Constitucional, habría que añadir a Alemania. Pero no se diría verdad si se afirma con ese carácter general en que el texto está formulado. La inmensa mayoría de tales sistemas jurídicos - ya hemos mostrado como también el sistema europeo de protección de derechos humanos ${ }^{39}$ y el Tribunal Supremo de EE. UU.- siguen negando, y con el sólido fundamento que queda sintetizado, que exista un derecho a darse positivamente la muerte.

\section{2. $\quad$ ¿Puede admitirse que una persona mate a otra fuera de la legítima defensa individual o social que se contempla en el art. 2 de la Convención Europea de Derechos Humanos?}

Aun en la hipótesis, que acabamos de rechazar por inadmisible, de que fuera legítimo, como parte de su autonomía personal, que una persona pudiera decidir poner término a su vida, de ningún modo cabría justificar que la acción letal estuviera a cargo de un tercero. Nadie debe poder matar a otro con ningún otro motivo que la proporcionada legítima defensa. El art. 2 de la

38 Véanse sus referencias en pp. 339-340 («en el ámbito europeo [...] sólo algunos estados", citando a pie de página los tres Estados del Benelux y Suiza), fuera de las cuales solo añade el caso de Canadá con la sentencia Carter de 2015 y un par de sentencias del Tribunal Constitucional de Colombia de 1997 y 2014 (p. 341). Sobre este país, vid., con posterioridad, Tomás-Valiente (2019: 301-328), quien, además, no deja de referirse a "desencuentros muy notables entre la propia Corte Constitucional, el legislador y últimamente también el Ministerio de Salud», como consecuencia de las sentencias del alto tribunal (p. 304).

39 Por lo que se incurre obviamente en error — discúlpese la reiteración - atribuyendo al Tribunal de Estrasburgo lo contrario, como parece hacer también Cańamares (ibid.), aun contradiciendo lo dicho por él mismo en el mismo trabajo, p. 340 y, básicamente también, en p. 341 y ss. 
Convención Europea dispone categóricamente que «nadie podrá ser privado de su vida intencionadamente» ${ }^{40}$. La rotundidad de esta afirmación no deja espacio a interpretaciones reductoras de su carácter absoluto. Precisamente por ello el mismo precepto - aparte de lo dispuesto por el art. 15.2 para los «actos lícitos de guerra»- especificó los límites o excepciones de tan apodíctica prohibición, que redujo al supuesto de «ejecución de una condena que imponga la pena capital dictada por un Tribunal al reo de un delito para el que se establece esa pena ${ }^{41}$, y a los casos en que la muerte «se produzca como consecuencia de un recurso a la fuerza que sea absolutamente necesario: a) en defensa de una persona contra una agresión ilegítima; b) para detener a una persona conforme a derecho o para evadir la evasión de un preso o detenido legalmente, y c) para reprimir de acuerdo con la ley, una revuelta o insurrección».

No parece, pues, que quepan otras excepciones. Lo que es lógica consecuencia del absoluto respeto que en cualquier caso merece la vida de cualquiera, que solo puede ceder en caso de ataque injusto - directo o indirecto- precisamente a la vida, que debe ser, en efecto, defendida y protegida con cuantos medios sean necesarios, incluida, si no hay otro medio, la muerte del injusto agresor, que, al atentar contra la vida de otro u otros - $\mathrm{o}$ contra el sistema institucional que justamente la protege- puede perder el derecho a conservar la propia. Pero es obvio que nada de esto es de posible aplicación a la eutanasia, es decir, a matar a alguien que lo pide, apelando a razones de una mal entendida compasión o de cualquier otro tipo. La vida de cualquiera es intocable mientras con ella no se agreda gravemente a otro o a

40 Nótese bien este adverbio, bien distinto del que se usa cuando se deduce de «la proclamación internacional y constitucional del derecho fundamental a la vida», que «lo comúnmente garantizado es, sobre todo, la prohibición de privar arbitrariamente de la existencia ajena» (Arruego, 2019: 119-120). Según este planteamiento habría homicidios arbitrarios y no arbitrarios, lo que estaría admitiendo, implícitamente, la posibilidad de matar por razones justificadas predeterminadas. $\mathrm{Y}$ es verdad que, como concreta el mismo art. 2 de la CEDH, y sintetizamos en el texto, hay supuestos en que la muerte de otro puede ser excepcionalmente legítima, pero asegurarla solamente contra lo que pueda tenerse por «arbitraria» privación de la vida de otro no puede sino favorecer una interpretación laxa de la protección debida a la vida.

41 El Protocolo n. 6 del CEDH, de 1983, abolió la pena de muerte, fuera del caso de guerra, como ya estaba establecido en Espańa y con rango constitucional por el art. 15 de la Constitución de 1978. Más recientemente, el Protocolo n.o 13 de 2002 la ha prohibido también en caso de guerra — como ya había hecho en España la Ley Orgánica 11/1995-, aunque su art. 4 deja cierto margen de maniobra a los Estados firmantes. 
algo institucionalmente determinante para la efectiva protección de la vida y los derechos de todos. El deseo o la voluntad de morir de alguien, por tanto, no pueden legitimar a nadie para matarle.

Ninguno de los tribunales que han sido objeto de nuestra atención en estas páginas se ha pronunciado nunca a favor de la posibilidad de que una persona pueda matar a otra que lo pida. De sus pronunciamientos - en particular del Tribunal Europeo, del de EE. UU. y del Constitucional españolse deduciría más bien, aunque con claridad diversa, que rechazan la legitimidad de tal posibilidad.

La asistencia al suicidio o la misma eutanasia han tratado de justificarse a veces en conexión con el derecho de toda persona a no ser objeto de tratos inhumanos y degradantes, que el art. 15 de la Constitución española garantiza como integrante del derecho a la integridad física y moral, pero que es reconocido, asimismo, aunque en contextos más limitados, junto con la prohibición de la tortura y de penas de tal índole - a las que se añaden esos tratos-, en la DUDH, art. 5, o en el CEDH, art. 3. Pero una tal conexión solo tendría alguna justificación para el caso de la obstinación terapéutica o de supuestos extremos de conservación vital enteramente artificial, que, ya hemos expuesto, deben distinguirse completamente de cualquier supuesto de suicidio. Los tratos inhumanos y degradantes no pueden, desde luego, sino referirse a actuaciones u omisiones humanas, no a hechos, procesos o efectos de la naturaleza no racional, aun cuando de la acción de esta, tanto la propia del cuerpo de cada persona humana como la circundante inerte o sin libertad, provengan tantas veces situaciones de gran sufrimiento, dolor, discapacidad o limitación para las personas humanas. El calificativo de inhumano y degradante en realidad solo parece poderse aplicar justamente a actuaciones u omisiones humanas, no de la naturaleza ajena a la libertad. Y, desde luego, si es el derecho a la integridad física y moral el que sustenta e incluye ese derecho a no ser objeto de tratos inhumanos y degradantes, como lo es, sin duda, en modo alguno parece que pudiera calificarse con un mínimo de coherencia, como trato inhumano o degradante, al no accederse a dar muerte a una persona que se encuentre en unas u otras circunstancias vitales más o menos reducidas o trágicas, es decir, a no acceder a violar de la manera más completa el derecho a la integridad física o moral que comporta privar a una persona de su misma vida. Lo que sería, por el contrario, auténtico trato inhumano y degradante sería precisamente esa acción de desposeer a alguien de sí mismo, de la vida como persona de la que, en el fondo, se predica aquella integridad física y moral, con la irreversibilidad de la muerte. Como lo sería también, sin duda, en medida que podrá variar, no proporcionar, a quien lo necesite, la atención, el auxilio, la asistencia, el cuidado curativo o paliativo, el acompańamiento 
humano que permita conservar o ayude a preservar lo mejor posible la vida y la mayor integridad física y moral posible mientras la vida no encuentre su término natural; lo que toca, además, ciertamente al derecho a la salud o a la asistencia sanitaria que la Constitución española reconoce en su art. 43, en cuyo efectivo disfrute, por ańadidura, como en el de todos los demás derechos que su título I otorga a todos los ciudadanos - empezando, obviamente, por el derecho a la vida y el derecho a la integridad física y moral—, su art. 49 obliga a los poderes públicos específicamente, como ya hemos recordado más arriba, a amparar especialmente a lo que allí denomina disminuidos físicos, sensoriales y psíquicos. El art. 50 obliga análogamente a los poderes públicos a promover el bienestar de los ciudadanos durante la tercera edad, atendiendo sus problemas especificos de salud, entre otras cosas.

\section{3. ${ }^{a}$ ¿No hay un deber social y del Estado de proteger la vida, también del que querría quitársela?}

Toda vida humana queda implicada en la solidaridad que une a todos los hombres, con una u otra intensidad, dependiendo de los diversos tipos de cercanía o proximidad que se producen en la práctica. Los vínculos de la sangre, conyugales y familiares, los religiosos, los del compañerismo, el trabajo o la amistad, los vecinales, locales, territoriales o nacionales, los de participación en grupos, asociaciones o instituciones políticas, culturales, deportivas, etc., y tantos otros, generan otros tantos niveles de solidaridad de densidad variable. La vida es de cada uno, pero viene de otros, es sostenida largo tiempo por otros, sale adelante con otros, se transmite a otros, sostiene las de otros, contribuye a las de otros, está enlazada con las de otros de muchos modos, con las que es interdependiente en la aludida relación de solidaridad. En una u otra medida todos nos debemos a todos. Reiterando lo ya expresado por insignes pensadores desde la antigüedad, lo dijo, acertadamente, uno de los jueces del Supremo americano, como vimos, aunque luego no fuera enteramente coherente con ello. De ahí, en suma, el deber de ayudarnos para sostenernos en esa vida que, en alguna medida, "pertenece» a todos, que explica la reacción instintiva para ayudar a quien lo necesita, sobre todo si se encuentra en grave riesgo, o para tratar de salvar la vida ajena cuando se la ve en riesgo inmediato de perderse. Y lo que explica que las legislaciones castiguen como delito la omisión de socorro, como ocurre con el art. 195 del Código Penal español, o incluyan entre las eximentes de responsabilidad penal, como también lo hace el Código Penal español en su art. 20.4. ${ }^{\circ}$ y 5. ${ }^{\circ}$, a quien «obre en defensa de la persona o derechos [...] ajenos» en caso de «agresión 
ilegítima», bajo determinadas condiciones, obviamente, de proporcionalidad, o, «en estado de necesidad, para evitar un mal [...] ajeno», también bajo determinadas condiciones.

Pero los deberes de solidaridad para con los demás no pueden incluir, en cambio, la ayuda a hacer el mal a otros o a hacérselo a uno mismo, menos aún a hacerse el mayor mal que alguien puede hacerse, que es acabar con su propia vida, sustento de cualquier posible bien. Dichos deberes obligan, en cambio, a no ceder, por ningún motivo, a cualquier petición de ayuda a darse la muerte, que será siempre algo contrario a esa solidaridad de la que hablamos, aunque ello pueda tener también intensidades diversas.

El Estado, los poderes públicos que sean, como proyección que son en cualquier caso de la sociedad misma que los erige a su servicio, principalmente para esclarecer, promover y garantizar los deberes jurídicos y los derechos correspondientes, no pueden por menos, obviamente, de estar también obligados a proteger la vida de todos y, desde luego, más en particular frente a cualquier acto homicida ${ }^{42}$, en lo que tienen precisamente una de sus más fundamentales justificaciones, y frente a, como decíamos, la omisión del deber de socorro por parte de otros. Nadie lo discute. Lo que algunos cuestionan, en cambio, y algunas muy pocas legislaciones o algún alto tribunal, como el Constitucional alemán hace pocos meses, han negado, es que ese deber de proteger la vida alcance también a protegerla frente a quien querría quitársela voluntariamente, al menos en determinados supuestos - evitar intensos sufrimientos o situaciones vitales que se consideran degradadas-, o incluso frente a quien quiera ayudar a tal suicidio.

Como dijimos, ni el TEDH ni el Constitucional español — tampoco el Supremo de Estados Unidos - han negado nunca que el Estado tenga ese deber de proteger la vida de cada cual frente a la acción de cualquier otro o incluso

42 Cuestionar, como se ha hecho, la naturaleza de derecho del derecho a la vida porque su titular nada podría hacer ante el Estado para requerir su protección una vez perpetrada eficazmente la acción letal (Arruego, 2019: 122-123) implica desconocer que, además de los modos que cualquier persona tiene de ejercer este derecho subjetivo con medidas jurídicas preventivas, y de las que, por descontado, podrá ejercer también contra la tentativa o la inducción al homicidio - como las legislaciones penales suelen prever para cualquier delito-, precisamente el valor objetivo fundamental que tiene ese derecho humano básico —en su condición subjetiva- justifica los derechos que para la persecución y castigo de quienes lo desconozcan suelen y deben otorgar los ordenamientos a determinadas instituciones públicas, sin que eso comporte en rigor vis expansiva alguna del derecho que trata de tutelarse (contra lo que afirma el mismo Arruego, ibid.). 
frente a sí mismo. Hasta ahora han negado, en cambio, que nadie tenga un derecho a ser ayudado para hacer posible el propio suicidio, excluyendo de esta calificación la opción, bajo estrictas condiciones, por la no aplicación de determinadas medidas terapéuticas o de mantenimiento artificial de la vida, aunque ello pueda llevar a una más próxima terminación natural de esa misma vida. Y no han dejado de advertir, con una u otra amplitud y detalle — con particular concreción y extensión la jurisprudencia americana-, sobre los graves riesgos que para la debida valoración y protección de toda vida humana representaría cualquier apertura a una legitimación de la ayuda al suicidio.

\section{BIBLIOGRAFÍA}

Aristóteles (2005). Ética a Nicómaco. Madrid: Alianza Editorial. Disponible en: https://bit. ly/3x1XiOl.

Arruego, G. (2019). Los confines del derecho fundamental a la vida. Revista Española de Derecho Constitucional, 115, 11-137. Disponible en: https://doi.org/10.18042/cepc/ redc.115.04.

Cañamares Arribas, S. (2016). La reciente jurisprudencia del Tribunal de Estrasburgo y del Tribunal Supremo en Canadá en relación con el derecho a la muerte digna. Revista Española de Derecho Constitucional, 108, 337-356. Disponible en: https://doi. org/10.18042/cepc/redc.108.11.

De Aquino, T. (1274). Summa Theologiae, II-II. Disponible en: https://hjg.com.ar/sumat/.

De la Torre Díaz, J. (2019). La eutanasia: siete argumentos para pensar. El Cronista del Estado Social y Democrático de Derecho, 79, 22-27.

Gerards, J. (2006). Right to life. En P. Van Dijk, F. Van Hoof, A. Van Rijn y L. Zwaak (eds.). Theory and Practice of the European Convention on Human Rights (pp. 353-380). Antwerp: Intersentia.

González Pérez, J. (1986). La dignidad de la persona. Madrid: Civitas.

- (2017). Sobre el derecho a vivir y el derecho a morir. En J. C Laguna de Paz, I. Sanz Rubiales, e I. M.a de los Mozos y Touya. Derecho Administrativo e Integración Europea, I (El ser de la Administración Pública) (pp. 207-219). Madrid: Reus.

Grabenwarter, Ch. (2014). European Convention on Human Rights (Commentary). München: Beck-Hart-Nomos-Helbing Lichtenhahn. Disponible en: https://doi. org/10.5771/9783845258942.

Kant, M. (1942). Fundamentación de la metafísica de las costumbres. Madrid: Espasa-Calpe.

Marcos del Cano, A. M. ${ }^{a}$ (2019a). La eutanasia: propuesta de regulación en Espańa. En A. M. ${ }^{a}$ Marcos del Cano y J. de la Torre (eds.). Y de nuevo la eutanasia. Una mirada nacional e internacional (pp. 53-78). Madrid: Dykinson. Disponible en: https://doi. org/10.2307/j.ctvfb6zvm.5.

- (2019b). ¿Es necesaria la regulación jurídica de la eutanasia en España? El Cronista del Estado Social y Democrático de Derecho, 79, 12-21. Disponible en: https://doi. org/10.2307/j.ctv103xbz7.5. 
Medina Morales, D. (2013). Muerte digna - Vida digna. Una reflexión - Un debate. Cuadernos de Bioética, 24 (3), 399-416.

Ochoa Ruiz, N. (2018). Tribunal Europeo de Derechos Humanos: Asunto Charles Gard y otros c. Reino Unido, demanda n. ${ }^{\circ}$ 39793/17, decisión de 27 de junio de 2017. Revista Aranzadi Doctrinal, 1, 129-140.

Oehling de los Reyes, A. (2011). El concepto constitucional de dignidad de la persona (Forma de comprensión y modelos predominantes de recepción en la Europa continental). Revista Española de Derecho Constitucional, 91, 135-178.

Prieto Álvarez, T. (2005). La dignidad de la persona (Núcleo de la moralidady el orden públicos, limite al ejercicio de libertades públicas). Madrid: Thomson Civitas.

(2017). Luces y sombras de la integración europea en derechos de la persona. En particular, el riesgo de que la base de sistema jurídico se traslade desde la dignidad humana a la autonomía personal. En J. C Laguna de Paz, I. Sanz Rubiales e I. M. a de los Mozos y Touya. Derecho Administrativo e Integración Europea, I (El ser de la Administración Pública) (pp. 187-206). Madrid: Reus.

Rey Martínez, F. (2019). ¿El derecho a la vida es un derecho disponible por parte de su titular? El Cronista del Estado Social y Democrático de Derecho, 79, 28-35.

Rodríguez Portugués, M. (2020). Eutanasia y libre determinación de la personalidad. En A. J. Sánchez Sáez (coord.). Dignidad y vida humana: eutanasia, gestación subrogada y transhumanismo (pp. 231-257). Cizur Menor, Navarra: Aranzadi-Thomson-Reuters.

Sánchez Sáez, A. J. (2020). Dignidad y vida humana: eutanasia, gestación subrogada y transhumanismo. Cizur Menor, Navarra: Aranzadi-Thomson-Reuters.

Serna, P. (1995). La dignidad de la persona como principio de Derecho Público. Derecho y Libertades, 4, 287-306.

- (1999). La dignidad de la persona: un estudio jurisprudencial. Persona y Derecho, 41, 139-196.

- (2005). La dignidad humana en la Constitución Europea. Persona y Derecho, 52, 13-77.

Tomás-Valiente Lanuza, C. (2014). La dignidad humana y sus consecuencias normativas en la argumentación jurídica: ¿un concepto útil? Revista Española de Derecho Constitucional, 102, 167-208.

(2019). La evolución del derecho al suicidio asistido y la eutanasia en la jurisprudencia constitucional colombiana: otra muestra de una discutible utilización de la dignidad. Revista Española de Derecho Constitucional, 116, 301-328. Disponible en: https://doi. org/10.18042/cepc/redc.116.10. 